\title{
Fungi Associated With Persistent Cough In Immunocompromised Hosts In Jos And Environ
}

\author{
O. Ojo Bola, S. A. Junaid, F. B. Ajimojuowo, A. A. Okunnuga, N. A. Okunnuga, D. E. Oguntunnbi, \\ O. Jegede, and L. T. Oguntunnbi
}

\begin{abstract}
This study was conducted to determine the fungi associated with persistent cough in immunocompromised patients attending Jos University Teaching Hospital (JUTH) and Vom Christian Hospital both in Plateau State. Hundred (100) immunocompromised patients with persistent cough were selected by random sampling. The sputum samples were collected and assayed for fungi using standard methods. The degree of disparity was analyzed using statistical method. Four different fungi were isolated from sputum of 37 (37\%) immunocompromised patient with persistent cough, with Candida albicans been the highest $18(48.6 \%)$ followed by Aspergillus niger 12 (32.4\%), Cryptococcus neoformans 5 (13.5\%) and Penicilium species 2(5.4\%). Male subjects 22 $(22 \%)$ were more susceptible to fungi associated cough than female $15(15 \%)$ with significant difference $(P$ value 0.026$)$. HIV, Tuberculosis and co-infection of both (HIV and TB) and prolong use of antibiotics were more predisposing factor associated with fungi related cough. These isolates were tested on 5 antifungal drugs. Ketoconazole and intraconazole were most susceptible to $83.8 \%$ of isolates, Amphotericin B had $\mathbf{5 4 . 1 \%}$ susceptible while Griseofulvin and Vericonazole were 18.9\% susceptible to the isolates. However, in managing the immunocompromised patient, there is a need for antifungal prophylaxis and sending of sample of immunocompromised host with persistent cough not only for bacteriological analysis but also mycological evaluation.
\end{abstract}

Index Terms - Fungi, Persistent cough, immunocompromised host, Jos.

\section{INTRODUCTION}

Fungi are microscopic plant organisms that consist of cells such as mould, mildew and yeast. They cannot produce their own food; thus, they behave as either parasite or saprophytes, absorbing nutrients from organic matter, such as human and animals [1]. They are present everywhere indoor and outdoor environment. The most common symptoms of fungal exposure are runny nose, eye irritation, cough, congestion and aggravation of asthma [2].

Invasive fungal disease continues to be a significant

Published on June 24, 2020

O. Ojo Bola, Federal Teaching Hospital, Nigeria.

(corresponding e-mail: ojobolaoluwatosin01@ gmail.com).

S. A. Junaid, Federal College of Veterinary and Medical Laboratory Technology, Nigeria.

F. B. Ajimojuowo, College of Health Sciences and Technology, Nigeria.

A. A. Okunnuga, Federal Teaching Hospital, Nigeria.

N. A. Okunnuga, University of Medical Science Teaching Hospital, Nigeria.

D. E. Oguntunnbi, Federal Teaching Hospital, Nigeria.

O. Jegede, Federal Teaching Hospital, Nigeria.

L. T. Oguntunnbi, Obafemi Awolowo University Teaching Hospital Complex, Nigeria. problem among immunocompromised patients. Most fungal infections are caused by commonly recognized opportunistic fungi [3]. Opportunistic fungi are generally harmless in its normal environment but become pathogenic in immunocompromised host [4], [5]. A compromised host is a host seriously debilitated and has lowered resistance to infection [5]. There are many causes of this condition. They include: Malnutrition, Alcoholism, Cancer, Diabetes, Leukemia or some other infectious disease, trauma from surgery or injury, an altered microbiota with prolong use of antibiotics, immune suppression drugs, virus (HIV), hormones, genetic deficiency, old age [6].

Persistent cough can be debilitating, social distressing and adversely impair quality of life [7]. Among these opportunistic fungal infections are Candida albicans, Cryptococcus neoformans, Aspergillus fumigatus, Mucor $\mathrm{sp}$ (Mucormycosis), and Pneumocystis carinii [8]. Fungal ball is one of leading cause of haemopytsis in Indian [9].

Incidence of systemic mycoses in patients with suspected tuberculosis, attending Infectious Diseases Hospital (IDH) and Murtala Mohammed Specialist Hospital (MMSH), Kano, Nigeria between May 2003 and May 2004 has been reported. The implication of the investigation revealed that some cases of tuberculosis may be compounded with mycosis caused by Aspergillus fumigatus [10].

However, persistent cough is often mis diagnosed by laboratory worker and even some clinicians are guilty of prescribing antibiotics to immunocompromised patients suffering from persistent cough; supposing, they have contracted bacteria infection (particularly TB). It has been observed that some patients that have low immunity suffers persistent cough which might not be bacterial, viral and parasitic origin but some opportunistic fungi. In line with this, the objectives are to:

1) isolate and identify fungi etiologic agents associated with persistent cough in immunocompromised host in the study population and location.

2) determine the prevalence of fungi associated with persistent cough in immunocompromised host.

3 ) carry out in vitro antifungal sensitivity on etiologic agents isolated.

4) evaluate the Demographic association with the persistent cough and the predisposing factor.

\section{MATERIALS AND METHODS}

\section{A. Study Area}

The study areas for this work were Jos University Teaching Hospital and Vom Christian Hospital located in Jos North and Jos South Local Government Area 
respectively.

\section{B. Study Population}

The study population comprised HIV patient, TB patient and patient on prolong antibiotics that were diagnosed as immunocompromised with persistent cough.

\section{Ethical Consideration, Questionnaire And Informed Consent}

The ethical clearance for this research was gotten from Jos University Teaching Hospital (JUTH) ethical committee after due processes had been followed. Questionnaire to obtain the demographic characteristics and other relevant information to the study as well as an informed consent were administered to the participant.

\section{Sample Collection}

Sequel to the identification of the immunocompromised patient with persistent cough, sterile universal bottles were given to the patients, instructed on the type of sample and aseptic condition required. The sputum samples collected were brought to the laboratory as soon as possible.

\section{E. Sample Processing}

Direct Mount preparation was done with $10 \% \mathrm{KOH}$ using method described by [11].

The sputum sample was mixed very well and a sterile applicator stick was used to pick small quantity which was seeded on the middle of plates of Sabouraud's dextrose agar and Potato dextrose agar and allowed to deep in. Duplicate cultures were made, and the plates were incubated aerobically at room temperature and at $37^{\circ} \mathrm{C}$. Culture plates were then examined daily for fungal growth for period of up to 3 weeks. Cultures were held for 30 days before discarded as negative result. Colonies growing outside the inoculated area were regarded as contaminant [11].

\section{F. Characterization And Identification}

1. Macroscopy and Microscopy examinations were carried out using method described by [12].

2. Germ tube test.

This test was used for identification of $C$. albicans. A known C. albicans was set as control [12], [13].

3. Negative staining method using Indian ink.

This test was used for the identification of Cryptococcus neoformans. A known Cryptococcus neoformans was set as control [14].

4. Lactophenol cotton blue

Needle mounting method was used to demonstrate other fungi growth and this was observed microscopically for macro conidia, micro conidia, Chlamydosphore, hyphae which may appear spiral, pectinate, anther-like [12].

\section{G. Biochemical Test}

Fermentation and Assimilation test were done to further identify the yeast and yeast like organisms [13].

\section{H. Source Of Antifungal Drugs}

A total of five different antifungal drugs were obtained from pharmacies in Jos and environ with their concentration. They are: Amphotericin B (200 mg) (manufactured by PT. interbat, Indonesia), Ketoconazole (200 mg) (Nimet Pharm. Nigeria), Griseofulvin (500 mg) (PT. interbat, Indonesia),
Intraconazole (200 $\mathrm{mg}) \quad$ (PT. interbat, Indonesia), Voriconazole (200 mg) (Nimet Pharm. Nigeria).

All stock solutions were prepared in $100 \%$ dimethyl sulfoxide at a concentration of $800 \mu \mathrm{g} / \mathrm{ml}$. They were labeled accordingly and frozen at $-20^{\circ} \mathrm{C}$ until when needed [14], [15].

\section{Preparation Of Inoculums}

\section{Mould}

Stock inoculums suspensions of the moulds were prepared from 15 day-old culture grown on culture plates. Mature colonies were covered with approximately $10 \mathrm{ml}$ of sterile normal saline $(0.85 \%)$ by scrapping the surface with of pipette. The resulting mixtures of conidia and hyphae fragments were transferred to sterile tube. The heavy particles were then allowed to settle for 15 minutes at room temperature. The supernatant was decanted and adjusted with normal saline to about No 1 Mac farland turbidity. Each suspension was diluted 1:50 in nutrient broth to obtain final inoculums twice (1:100) [14], [15].

2. Yeast

Stock inoculums of yeast were prepared by picking a colony of yeast emucified in normal saline. The turbidity was adjusted to $0.5 \mathrm{Mc}$ Farland standards (1Mcfarland standard for C. neoformans) [14], [16].

\section{J. Mould Susceptibility Testing}

Working standard of antifungal drugs $(16 \mu \mathrm{g} / \mathrm{ml})$ [16], each were diluted 1:50 (1 volume of drugs to 49 volumes of medium) with medium cooled to $40{ }^{\circ} \mathrm{C}$ and mixed thoroughly by shaking and the mixture were poured into a Petri dish. Control plates were prepared containing 1 volume of dimethyl super oxide to 49 volumes of medium and blank was also prepared as control by adding 1volume of distilled water to 49 volumes of medium. They were both allowed to solidify. A loopful of well homogenized inoculums prepared in above was spread over the surface of the plate and was then incubated at room temperature and was observed daily, the test plates were read after the growth has become visible on the blank control plates [15], [17].

\section{K. Yeast Susceptibility Testing}

Clinical Laboratory and Standard Institute methods is a broth micro dilution, but it is labour-intensive and cumbersome. However, disk or agar diffusion method most attractive alternative method so far investigated and it is also well suited for routine use in mycology laboratories [18]. Agar diffusion method was used for this research work.

The suspension of yeast inoculums prepared in above were poured over a dried Potato Dextrose Agar plate previously dried at $37^{\circ} \mathrm{C}$ for 10 minutes, excess suspension were decanted and the plate was allowed to dry. A sterile cork borer was then used to make 6 holes which were labeled according to the antifungal drugs under test. About 2 drops of antifungal drugs each was then dispensed into respective hole avoiding over floating. Distilled water was dispensed into the 6th hole which serves as control. It was then incubated as approved by CLSI (Candida sp for $48 \mathrm{hrs}$ and C. neoformans 72 hours) [18]. 


\section{RESUlTS AND DisCUSSION}

Response rate

A total of 100 questionnaires and consent form were distributed to patient screened and out of 100 questionnaires distributed, 100 were returned indicating a $100 \%$ response rate.

Table 1 shows the prevalence of fungi associated with persistent cough in immunocompromised patient. It reveals that $37(37.0 \%)$ out of 100 immunocompromised patients tested were positive for fungi materials whereas $63(63.0 \%)$ were negative showing absent of fungi growth. For this number of people to be infected, it is significant (P-value 0.009 , chi square $6.760 \mathrm{df} 1$ ) since invasive fungal infection are associated with high morbidity and mortality, thereby increasing the challenge for management of immunocompromised patient [5]. This agree with previous work of [19] that had the frequency of fungi isolated in sputum of immunocompromised patient as $42.9 \%$.

TABLE I: PREVAlence Of Fungi Associated With PeRsistent Cough

\begin{tabular}{lccc}
\hline \hline & Frequency & $\begin{array}{c}\text { Percentage } \\
(\%)\end{array}$ & P-Value \\
\hline Positive & 37 & 37 & 0.009 \\
Negative & 63 & 63 & \\
\hline Total & 100 & 100 & \\
\hline \hline
\end{tabular}

The distribution of fungi in relation to the study population and location shows that $16(32.0 \%)$ out of 50 samples collected from Vom Christian Hospital were positive for fungi growth while 21 (42.0\%) out of 50 samples collected from Jos University Teaching Hospital were positive for fungi growth as shown in the table 2 . Despite the prevalence of these organisms, there was no significant difference in their existence in study location (Table II) (P-value 0.300 chi square $1.073 \mathrm{df} 1$ ). This might be due to rural-urban migration for better medical treatment.

TABLE II: PREVALENCE OF Fungi To The STUdy LOCATION

\begin{tabular}{lcccc}
\hline \hline Location & Positive & Negative & Total \% & P-Value \\
\hline VOM & 16 & 34 & 50 & \\
$\%$ of total & 32 & 68 & 100 & 0.300 \\
JOS & 21 & 29 & 50 & \\
$\%$ of total & 42 & 58 & 100 & \\
\hline Total & 37 & 63 & 100 & \\
\hline \hline
\end{tabular}

The breakdown of the type of fungi isolated from the sputum of immunocompromised host is shown in table 3 . It reveals that $C$. albicans had the highest with 18 (48.6\%), followed by Aspergillus niger with 12 (32.4\%), Cryptococcus neoformans $5(13.5 \%)$ and Penicillium species were $2(5.4 \%)$ in the sputum sample analyzed. However, the distribution of fungi in the study population (Table III) shows that $C$. albicans is the most prevalent with overall frequency of $18(48.6 \%)$ which agree with previous work of [20]. This may be because $C$. albicans has possibility of oropharngeal colonization [19]. A. niger was next with overall frequency of $12(32 \%), C$. neoformans had overall frequency of $5(13.5 \%)$ and Penicillium species 2 $(5.4 \%)$ which are significant (P-value 0.01 , chi square 0.716 df 3 ). This may be attributed to the fact that the fungi are distributed through the world and are the most common fungi causing life threatening infections in immunocompromised patient particularly-HIV/AIDS. It has also been documented that emergence of Candidiasis, Cryptococcosis, Aspergillosis and Penicillosis and other Pheolyphomycosis among HIV patient on steroid therapy, had a dual infection with A. niger and S. aureus [2].

\begin{tabular}{lccc}
\multicolumn{4}{c}{ TABLE III: PREVALENCE WITH TYPE OF FUNGI } \\
\hline \hline Type of Fungi & Frequency & Percentage $(\%)$ & P-Value \\
\hline C. neoformans & 5 & 13.5 & \\
A. niger & 12 & 32.4 & 0.01 \\
C. albicans & 18 & 48.6 & \\
Penicillium $\mathrm{sp}$ & 2 & 5.4 & \\
\hline Total & 37 & 100 & \\
\hline \hline
\end{tabular}

Table IV shows the prevalence of fungi in relation to demographic data. The age group 21-30, 31-40, 41-50, and $61-70$ years had $8(8.0 \%)$ of the fungi positive sputum while age 11-20 and 51-60 had $0(0 \%)$ and $5(5.0 \%)$ respectively.

The prevalence to sex shows that male had $22(22.0 \%)$ of fungi positive sputum while female had 15 (15.0\%). Gender wise distribution of positive subject (Table IV) showed significant difference between male and female observed in study population which probable might cause by exposure or involving of male subject to area or occupation where they inhale the spore of these organism [9].

TABLE IV: PREVALENCE OF FUnGI IN RELATION TO DEMOGRAPHIC DATA

\begin{tabular}{|c|c|c|c|c|}
\hline & $\begin{array}{c}\text { Positive } \\
(\%)\end{array}$ & $\begin{array}{c}\text { Negative } \\
(\%)\end{array}$ & Total $(\%)$ & P-Value \\
\hline \multicolumn{5}{|l|}{ Age (Years) } \\
\hline $11-20$ & $0(0)$ & $1(1)$ & $1(1)$ & \multirow{7}{*}{0.854} \\
\hline $21-30$ & $8(8)$ & $10(10)$ & $18(18)$ & \\
\hline $31-40$ & $8(8)$ & 17 (17) & $25(25)$ & \\
\hline $41-50$ & $8(8)$ & $12(12)$ & $20(20)$ & \\
\hline $51-60$ & $5(5)$ & $6(6)$ & $11(11)$ & \\
\hline $61-70$ & $8(8)$ & 17 (17) & $25(25)$ & \\
\hline Total & 37 (37) & $63(63)$ & $100(100)$ & \\
\hline \multicolumn{5}{|l|}{ Occupation } \\
\hline Civil servant & $5(5)$ & $11(11)$ & $16(16)$ & \multirow{4}{*}{0.142} \\
\hline Farmer & $27(27)$ & $34(34)$ & $61(61)$ & \\
\hline Business & $5(5)$ & $18(18)$ & $23(23)$ & \\
\hline Total & $37(37)$ & $63(63)$ & $100(100)$ & \\
\hline \multicolumn{5}{|l|}{ Sex } \\
\hline Male & $22(22)$ & $23(23)$ & $45(45)$ & \multirow{3}{*}{0.026} \\
\hline Female & $15(15)$ & $40(40)$ & $55(55)$ & \\
\hline Total & $37(37)$ & $63(63)$ & $100(100)$ & \\
\hline \multicolumn{5}{|l|}{ Marital status } \\
\hline Married & 37 (37) & $56(56)$ & $93(93)$ & \multirow{4}{*}{0.110} \\
\hline Single & $0(0)$ & $1(1)$ & $1(1)$ & \\
\hline Engaged & $0(0)$ & $6(6)$ & $6(6)$ & \\
\hline Total & $37(37)$ & $63(63)$ & $100(100)$ & \\
\hline \multicolumn{5}{|l|}{ Education } \\
\hline Primary & $14(14)$ & 24 (24) & $38(38)$ & \multirow{5}{*}{0.132} \\
\hline Secondary & $16(16)$ & $36(36)$ & $52(52)$ & \\
\hline Tertiary & $4(4)$ & $2(2)$ & $6(6)$ & \\
\hline None & $3(3)$ & $1(1)$ & $4(4)$ & \\
\hline Total & 37 (37) & $63(63)$ & $100(100)$ & \\
\hline
\end{tabular}

Prevalence to occupation reveals that civil servant had 5 (5.0\%), farmer 27 (27.0\%), Bussiness 5 (5.0\%) fungi positive sputum. However, distribution of the fungi in the sputum of the study population shows that married had 37 (37.0\%) while both single and Divorced had $0(0.0 \%)$ positive for fungi growth. However, occupational 
distribution (Table IV) showed no significant difference (Pvalue 0.142 ) among the occupation listed, indicating that this prevalence does not really matter the occupation but probably due to the fact that most civil servant and Businessmen also involve themselves in farming activities in the study population. Other demographic data (Age, Education, Marital Status) were also linked with the prevalence of these fungi in the study population. It noticed that there was no significant difference as regards to age groups (Table IV) indicating that any age might be susceptible to the fungi, most especially when the individual is immunocompromised. Subjects that were married had the highest prevalence of 37 (37\%) unlike single and divorced with $0(0 \%)$ which agreed with previous work of [9].

The associated risk factor of patient studied is shown in Table V. HIV, Tuberculosis, HIV and Tuberculosis, prolong use of antibiotics and old age were the risk factor in this work. HIV patients had $11(11.0 \%)$ positive for fungi growth, Tuberculosis patients and patient on prolong use of antibiotics had $2(2.0 \%)$ and old age had $14(14.0 \%)$ positive for fungi growth. Prevalence with respect to available risk factor were also demonstrated (Table V) with HIV, TB and Co-infection (HIV and TB), prolong use of antibiotics were significant risk factor (P-value 0.014, 0.000, 0.000, 0.007 respectively) unlike old age which did not appear to be significant. This agreed with previous work of [19] and [20].

TABLE V: ASSOCIATED RISK FACTORS

\begin{tabular}{|c|c|c|c|}
\hline Location & Frequency & $\begin{array}{c}\text { Percentage } \\
(\%)\end{array}$ & P-Value \\
\hline \multicolumn{4}{|c|}{ HIV Status } \\
\hline Positive & 11 & 11 & \multirow[t]{3}{*}{0.014} \\
\hline Negative & 26 & 26 & \\
\hline Total & 37 & 37 & \\
\hline \multicolumn{4}{|c|}{ Tuberculosis } \\
\hline Positive & 5 & 5 & \multirow[t]{3}{*}{0.000} \\
\hline Negative & 32 & 32 & \\
\hline Total & 37 & 37 & \\
\hline \multicolumn{4}{|c|}{ HIV/Tuberculosis } \\
\hline Positive & 5 & 5 & \multirow[t]{3}{*}{0.000} \\
\hline Negative & 32 & 32 & \\
\hline Total & 37 & 37 & \\
\hline \multicolumn{4}{|c|}{$\begin{array}{l}\text { Prolong use of } \\
\text { antibiotics }\end{array}$} \\
\hline Positive & 2 & 2 & \multirow{3}{*}{0.000} \\
\hline Negative & 35 & 35 & \\
\hline Total & 37 & 37 & \\
\hline \multicolumn{4}{|c|}{ Old age (61-70) } \\
\hline Positive & 14 & 14 & \multirow{3}{*}{0.139} \\
\hline Negative & 23 & 23 & \\
\hline Total & 37 & 37 & \\
\hline
\end{tabular}

Table VI reveals the overall susceptibility of 37 fungi isolates to antifungal drugs. Ketoconazole and Intraconazole were susceptibile to 31 isolates $(83.8 \%)$, Amphotericin B was susceptible to $20(54.1 \%)$ isolates while Griseofulvin and Vericonazole were susceptible to 7 isolates (18.9\%). The frequency of invasive mycoses has increase dramatically during the past two decades owing to the medical advances such as Broad-spectrum antimicrobial agent, invasive medical device, organ transplantation, HIV epidemic and expanding aging population [20].
TABLE VI: OVERALL SUSCEPTIBILITY OF ISOLATES TO ANTIFUNGAL DRUGS

\begin{tabular}{lccc}
\hline \hline Drugs & $\begin{array}{c}\text { No of } \\
\text { isolate }\end{array}$ & $\begin{array}{c}\text { No susceptible } \\
(\%)\end{array}$ & $\begin{array}{c}\text { No of } \\
\text { Resistance }(\%)\end{array}$ \\
\hline Ketoconazole & 37 & $31(83.8)$ & $6(16.2)$ \\
Amphotericin B & 37 & $20(54.1)$ & $17(45.9)$ \\
Griseofulvin & 37 & $7(18.9)$ & $30(81.1)$ \\
Vericonazole & 37 & $7(18.9)$ & $30(81.1)$ \\
Intraconazole & 37 & $31(83.8)$ & $6(16.2)$ \\
\hline \hline
\end{tabular}

Treatment of fungal infection can now be guided by in vitro susceptibility testing. However, susceptibility testing of fungi is not considered a routine testing procedure in many laboratories and is not promptly available. Nevertheless, susceptibility testing is especially helpful in deep infection [14].

However, there are limited but increasing number of antifungal that can be used to treat mycotic infection. Most have one or more limitation such as side effect, narrow antifungal spectrum and poor penetration of certain tissue [21].

The antifungal susceptibility of isolates was carried out. Some azole group (Ketoconazole and Intraconazole) were found out to be more susceptible to fungi isolated. This agreed with previous work of [15]. This is because some azoles antifungal are broad spectrum and have good penetration power of certain tissue [21]. For organisms that are resistant to these two azoles could be due to the variation of strain of fungi isolates which is supported by previous work of [16] that documented variation in response to drugs based on frequency of occurrence of species such as azoleresistant strain.

However, the resistant of Amphotericin B to some isolates might be due to ability of the organisms to prevent binding of the drugs to ergo sterol in the membrane which is the active site of the drugs [17]. On the other hand, Griseofulvin resistant to some isolates might be caused by the ability of organisms to prevent interfering with microtubule assembly. Since the active site of the drug is microtubule assembly [17]. Vericonazole that showed little susceptibility to the isolates could be due to poor penetration of tissue by some drugs which was earlier discussed by [21] and azole-resistant starin of Candida spp [16].

Table VII shows the susceptibility of fungi isolates to antifungal drugs with their MIC. Five different drugs were used against 37 fungi isolates. However, among the drugs used, Ketoconazole(MIC $0.20 \mathrm{ug} / \mathrm{ml}$ ) was found out to have the highest susceptibility to $\mathrm{C}$. albicans, followed by Intraconazole (MIC $0.16 \mathrm{ug} / \mathrm{ml}$ ), Amphotericin B (MIC 0.16 $\mathrm{ug} / \mathrm{ml}$ ), Vericonazole (MIC $0.30 \mathrm{ug} / \mathrm{ml}$ ) and the least susceptible was Griseofulvin (MIC $0.20 \mathrm{ug} / \mathrm{ml}$ ). The antifungal biogram on $\mathrm{A}$. niger reveals that Intraconazole (MIC $0.16 \mathrm{ug} / \mathrm{ml}$ ) was found to be highest susceptible and Griseofulvin (MIC $0.25 \mathrm{ug} / \mathrm{ml}$ ) was the least susceptible. C. neoformans was found to have highest susceptibility to Intraconazole (MIC $0.16 \mathrm{ug} / \mathrm{ml}$ ) and Amphotericin B (MIC $0.16 \mathrm{ug} / \mathrm{ml})$, Vericonazole was resistant to all the neoformans isolates.

Ketoconazole(mic $0.25 \mathrm{ug} / \mathrm{ml}$ ) had highest susceptible to Penicillium spp, while griseofulvin (mic $0.25 \mathrm{ug} / \mathrm{ml}$ ), vericonazole (mic $0.16 \mathrm{ug} / \mathrm{ml}$ ) and intraconazole (mic $0.16 \mathrm{ug} / \mathrm{ml}$ ) were seen to have susceptible to only one 
Penicillium isolates, while amphotericin b was resistant to the two Penicillium spp isolated.

TABLE VII: SUSCEPTIBILITY OF FUNGI ISOLATES AT VARIOUS MIC TO ANTIFUNGAL DRUGS

\begin{tabular}{lcccc}
\hline Resistance & $\begin{array}{c}\text { Total } \\
\text { tested }\end{array}$ & No & Susceptible & $\begin{array}{c}\text { MIC } \\
\text { (ug/ml) }\end{array}$ \\
\hline Candida albicans & & & & \\
Ketoconazole & 18 & 16 & 0.20 & 2 \\
Amphotericin B & 18 & 7 & 0.16 & 11 \\
Griseofulvin & 18 & 3 & 0.20 & 15 \\
Vericonazole & 18 & 4 & 0.30 & 14 \\
Intraconazole & 18 & 14 & 0.16 & 4 \\
\hline Aspergillus niger & & & & \\
Ketoconazole & 12 & 10 & 0.25 & 2 \\
Amphotericin B & 12 & 9 & 0.30 & 3 \\
Griseofulvin & 12 & 1 & 0.25 & 11 \\
Vericonazole & 12 & 2 & 0.16 & 10 \\
Intraconazole & 12 & 12 & 0.16 & 0 \\
\hline Cryptococcus & & & & \\
neoformans & & & & \\
Ketoconazole & 5 & 3 & 0.20 & 2 \\
Amphotericin B & 5 & 4 & 0.16 & 1 \\
Griseofulvin & 5 & 2 & 0.20 & 3 \\
Vericonazole & 5 & - & - & 5 \\
Intraconazole & 5 & 4 & 0.16 & 1 \\
\hline Penicillium specie & & & & \\
Ketoconazole & 2 & 2 & 0.25 & 0 \\
Amphotericin B & 2 & 0 & - & 2 \\
Griseofulvin & 2 & 1 & 0.25 & 1 \\
Vericonazole & 2 & 1 & 0.16 & 1 \\
Intraconazole & 2 & 1 & 0.16 & 1 \\
\hline \hline & & & & \\
\hline & & & & \\
\hline & & & & \\
\hline
\end{tabular}

\section{CONCLUSION}

Since fungi invasive infection are associated with high morbidity and mortality rate, bring about increasing challenges for the management of immunocompromised patient, to this end more active screening in high risk groups should be done to avoid diagnostic delay. Risk factor like prolong use of multiple antibiotics and infection HIV should be restricted whenever possible. Timely use of antiretroviral drugs and other measure to improve immunity of HIV patient may also help to decrease the incidence of fungal infection in this population. There is also need for antifungal prophylaxis for these groups at risk. Above all there is a need for comprehensive clinical detail of immunocompromised patients sample sent to laboratory for analysis so as to guide against misleading result. It is therefore recommended that in investigating pulmonary infection in patient with immune deficiency, samples should also be sent to mycological laboratory with comprehensive clinical information for mycological evaluation

\section{ACKNOWLEDGMENT}

Bacteriology Department of National Veterinary Research Institute (NVRI), Dr Daniyam of Jos University Teaching Hospital (JUTH), Dr E Young, Australian Medical Practitioner in Vom Christian Hospital for the identification of patients used for this research work and all members of Vom Christian Hospital Laboratory.

\section{REFERENCES}

[1] D. K Leventin and O. Burge, "What are Fungi?" Fungal infection Treatment information. 32 (2): 5-7, (2007).

[2] R. I. Adams, M. Miletto, J. W. Taylor and T. D. Bruns, "Dispersal in microbes: fungi in indoor air are dominated by outdoor air and show dispersal limitation at short distances", J. International Society for Microbial Ecology, 1-12, (2013).

[3] K. Thakur, G. Singh, S. Agarwal, L. Rani, "Meningitis caused by Rhodotorula rubra in an human immunodeficiency virus infected patient" Indian Journal of Medical Microbiology, 25(2): 166-168, (2007).

[4] M. A. Pfaller, and D. J. Diekema. "Rare and Emerging Opportunistic Fungal Pathogens: Concern for Resistance beyond Candida albicans and Aspergillus fumigatus". Journal of Clinical Microbiology vol. 42 no. 10 4419-4431, (2004)

[5] T. H. Merritt and J. Segreti "The role of the infectious disease specialist in the diagnosis and treatment of primary immunodeficiency disease". Infect Dis Clin Pract.;19(5):316-325, (2011)

[6] L. M. Prescolt, J. P. Harley, and D. A. Klein "Human Disease caused by fungi and protozoa in review of Microbiology". 5th ed Mc GrawHill companies Inc publish. New York. Pp 941-978. (2002).

[7] S. U. Omar, G. B. Maria, J. P. Hema, C. Natascia, A. B. Mark, K. Marta, K. Dezso, and J. B. Peter, "Theobromine inhibit sensory nerve activation and cough". The FASEB J. 19: 231-233, (2005).

[8] L. Sung "Invasive fungal infections in children with cancer". J Pediatr.;156 (2):68-73. (2010)

[9] R. Jain, D. Agarwal, T. K. Lahiri, V. Tilak and A. Gulati, "Successful treatment of invasive pulmonary aspergillosis in an Immunocompetent host" Respirology 10(3): 393-5, (2007).

[10] N. T. Dabo and M. Yusha'u, "Incidence of Systemic Mycoses. In Patients With Suspected Tuberculosis in Kano, Nigeria". International Journal of Pure and Applied Science, 1(1): 35-39, (2010).

[11] J. Ochei and A. Kolhatkar, "Laboratory Techniques in mycology". In: Bulakh P.M. and Deshmukh, S.eds. Medical Laboratory Science Theory and Practise. 3rd edn. Tata McGraw-Hill publication. New Delhi. Pp 1056-1105, (2005)

[12] M. D. Mukhtar and M. Huda, "Prevalence of Tinea capitis in primary school and sensitivity of etiological agent to Pistia stratiotes extracts; Detection and isolation of C. albicans." Nig. J. Microbiol. 19(1-2): 412-419, (2005).

[13] R. S. Iyer, R. B. Pal, R. Y. Patel and D. D. Banker, "Polymerase Chain Reaction based diagnosis of systemic fungal infections and sensitivity testing of the fungal isolates". Indian J. Med. Microl. 20(3): 132-136, (2002).

[14] J. M. Wiley, "Fungal infections in pediatric immunocompromised patients: epidemiology, principles of treatment, an promising antifungal agents". J Pediatr. 156 (2):74-82, (2010).

[15] B. Fernandez-Torres, A. J. Carrillo, E. Martin, A. Del Palacio, M.K Moore, A. Valverde, M. Serrano, and J. Guarro, "In vitro Activities of 10 Antifungal against 508 Dermatophyte Strains". J. Antimicrob. Agents Chemother. 45 (9): 2524-2528, (2001).

[16] H. L. Hoffman and M. A. Pfaller, "In vitro Antifungal Susceptibility Testing". J Pharmacotherapy 21 (8s): 111-123, (2001).

[17] J. Lambourne, D. Agranoff, R. Herbrecht, P. F Troke, A. Buchbinder, F. Willis. "Association of mannose-binding lectin deficiency with acute invasive aspergillosis in immunocompromised patients". Clin Infect Dis. 15; 49(10):1486-91, (2009).

[18] Clinical and Laboratory Standards institute (CLSI). "Methods for the dilution, antimicrobial susceptibility test for bacteria. Approved standards. Ninth Editions(M09)", (2010).

[19] L. A. Shailaja, L. A. Pai, D.R. Mathur and V. Lakshmi, "Prevalence of bacterial and fungal agents causing lower respiratory tract infections in patient with cough". J of Microbiology 22: 28-33, (2004).

[20] M. N. Chowta, P. Adhikari, A. Rajeev, A. K. Shenoy, "Study of the risk factors and prevalence of invasive candidiasis in a tertiary care hospital'. Indian J. Crit. Med. 11: 67-73, (2007).

[21] E. Jawetz, J. L. Melnick, E. A. Adelberg, "Medical mycology". In: G. F. Brooks, J. S. Butel, S. A. Morse. eds. Review of Medical Microbiology. 23rd edn. Lange Medical Publication. Los Angeles California. pp 531-555. 